\title{
Intraoperative cardiopulmonary collapse despite prophylactic anticoagulation for thromboembolism
}

\author{
Ju Deok Kim, Chiachi Cheng, Dong Jin Shim, Doo Sik Kim, Sie Jeong Ryu, Yusom Shin \\ Department of Anesthesiology and Pain Medicine, Kosin University College of Medicine, Busan, Korea
}

Received May 11, 2018

Revised June 2, 2018

Accepted June 4, 2018

Corresponding author

Yusom Shin

Department of Anesthesiology and

Pain Medicine, Kosin University

College of Medicine, 262

Gamcheon-ro, Seo-gu, Busan

49267, Korea

Tel: +82-51-990-6283

Fax: +82-51-254-2504

E-mail: yusom2015@gmail.com

ORCID:

https://orcid.org/0000-0002-4829-0866

\begin{abstract}
Prophylactic anticoagulation for high-risk patients of pulmonary embolism (PE) prevails as acute PE potentially leads to hemodynamic instability resulting in death. Notwithstanding the adequate thromboprophylaxis, rarely, we may face a patient's critical condition with $\mathrm{PE}$. We report here on the patient given intraoperative cardiopulmonary resuscitation that the cause was revealed to be PE despite subcutaneous anticoagulant until the day before scheduled secondary operation. The 72-year-old male patient had already undergone first emergency surgery for right tibia and patella fractures without any problems. Albeit effective, prophylaxis for thromboembolism cannot guarantee PE prevention. With this sobering fact in mind, additionally, early diagnosis and prompt management of $\mathrm{PE}$, especially through interdepartmental coordination, should produce patients' best outcomes.
\end{abstract}

Keywords: Anticoagulants; Resuscitation; Venous thrombosis; Pulmonary embolism

\section{INTRODUCTION}

Because clinical occurrence of pulmonary embolism (PE) can be fatal without prompt management (e.g., immediate thrombolytic therapy), preventive prophylactic anticoagulation commonly is administered to patients at high risk of PE. Orthopedic surgery is a well-known significant risk factor for PE [1]. PE can occur at any time during the first operation or the secondary one [2]. Unfortunately, it is easily overlooked in the pretreatment phase, and its diagnosis is often more difficult, particularly in the intraoperative state. Herein, we report a case of cardiopulmonary resuscitation (CPR) resulting from PE that occurred during secondary orthopedic surgery despite preventive administration of adequate anticoagulants.

\section{CASE}

A 72-year-old male $(161 \mathrm{~cm}, 58 \mathrm{~kg})$ was scheduled for an elective operation for open reduction and internal fixation (ORIF) of right tibia and patella fractures due to a motorcycle accident. The patient has no other medical history except for benign prostatic hyperplasia. He had initially undergone an emergency closed reduction external fixation operation two weeks previously. Postoperatively, he had been on bed rest. An anticoagulant (dalteparin sodium 2,500 IU) had been administered by subcutaneous injection twice per day until the day before the secondary operation. The secondary operation, ORIF, performed under spinal anesthesia, required about two and a half hours. A tourniquet for surgery was wrapped

This is an Open Access article distributed under the terms of the Creative Commons Attribution Non-Commercial License (http://creativecommons.org/licenses/by-nc/4.0) which permits unrestricted noncommercial use, distribution, and reproduction in any medium, provided the original work is properly cited. Copyright (c) Medical Biological Science and Engineering. 
around the patient's right thigh. The vital signs were stable just before surgeon-directed tourniquet removal. Shortly thereafter, the patient's non-invasive blood pressure (BP) and heart rate decreased $(75 / 50 \mathrm{mmHg}, 110$ beats/min). Intravenous (IV) ephedrine $10 \mathrm{mg}$ and plasmalyte solution were concurrently and quickly delivered. The vital signs then stabilized for 15 minutes. However, soon the patient's peripheral oxygen saturation $\left(\mathrm{SpO}_{2}\right)$ decreased to $90 \%$ with symptoms such as chest discomfort, dyspnea, tachypnea, and agitation. Manual ventilation was performed using a facial mask with $100 \%$ oxygen and a sedative. Arterial blood gas analysis (ABGA) revealed the following: $\mathrm{pH}$ 7.32, arterial $\mathrm{O}_{2}$ partial pressure $\left(\mathrm{PaO}_{2}\right) 52 \mathrm{mmHg}$, arterial $\mathrm{CO}_{2}$ partial pressure $\left(\mathrm{PaCO}_{2}\right) 42$ $\mathrm{mmHg}$, bicarbonate $\left(\mathrm{HCO}_{3}\right) 21.6 \mathrm{mmol} / \mathrm{L}$, and oxyhemoglobin saturation $\left(\mathrm{SaO}_{2}\right) 83 \%$. The end-tidal $\mathrm{CO}_{2}$ partial pressure $\left(\mathrm{ETCO}_{2}\right)$ was $31 \mathrm{mmHg}$. Ephedrine bolus IV and continuous phenylephrine IV were administered to maintain hemodynamic stability, and the patient's vital signs were closely monitored. The $\mathrm{SpO}_{2}$ steadily decreased to $81 \%$, and endotracheal intubation was performed. Continuous IV dopamine was maintained for hemodynamic stability. The new ABGA results were as follows: $\mathrm{pH}$ 7.27, $\mathrm{PaO}_{2} 64 \mathrm{mmHg}, \mathrm{PaCO}_{2} 54$ $\mathrm{mmHg}, \mathrm{HCO}_{3} 24.8 \mathrm{mmol} / \mathrm{L}, \mathrm{SaO}_{2} 89 \%$. The $\mathrm{ETCO}_{2}$, meanwhile, was $25 \mathrm{mmHg}$. Arterial cannulation of the left radial artery was performed, and continuous IV norepinephrine was introduced, due to the patient's continuing hemodynamic instability. The updated ABGA findings were as follows: $\mathrm{pH} 6.98, \mathrm{PaO}_{2}$ $75 \mathrm{mmHg}, \mathrm{PaCO}_{2} 82 \mathrm{mmHg}, \mathrm{HCO}_{3} 19.3 \mathrm{mmol} / \mathrm{L}, \mathrm{SaO}_{2} 84 \%$. The $\mathrm{ETCO}_{2}$ was $20 \mathrm{mmHg}$. A pulmonologist, cardiologist, and thoracic surgeon, immediately summoned, made a consensus diagnosis of likely PE. Consequently, 2,500 units of unfraction- ated heparin as mixed with normal saline $500 \mathrm{~mL}$ were injected. Simultaneously, transthoracic echocardiography detected right-ventricular failure, though the existence of an embolus was not confirmed. Despite continuous infusion of vasopressors, systolic BP dropped to below $40 \mathrm{mmHg}$, and no arterial waveforms were detected. CPR was initiated, ten minutes after which, the patient's vital signs were restored $(140 / 80 \mathrm{mmHg}$, 130 beats/min, $\mathrm{SpO}_{2}$ 93\%). Obtained chest computed tomography and pulmonary angiography images were examined under the supervision of a surgeon and two anesthesiologists (the latter on hand in case of worsening vital signs). The images indicated a large bilateral pulmonary thromboembolus (Fig. 1). A total of 200,000 units of urokinase were promptly injected, and extracorporeal membrane oxygenation (ECMO) was applied. The ABGA results were as follows: $\mathrm{pH} 7.43, \mathrm{PaO}_{2}$ $64 \mathrm{mmHg}, \mathrm{PaCO}_{2} 37 \mathrm{mmHg}, \mathrm{HCO}_{3} 25.1 \mathrm{mmol} / \mathrm{L}, \mathrm{SaO}_{2} 93 \%$. The ECMO was maintained for 3 days, and several aspiration thrombectomies (Fig. 2) were performed. After 6 days in the intensive care unit, the patient was transferred to the general ward and discharged 22 days alter without further complications.

\section{DISCUSSION}

Early diagnosis of PE is directly linked to more favorable prognosis. However, non-specific initial symptoms such as chest discomfort render diagnosis difficult. For this reason, caution must be exercised both intraoperatively and anesthesiologically. The so-called Virchow's triad represents the pathophysiology of venous thromboembolism, which is associated with the three conditions of venous stasis, endothelial

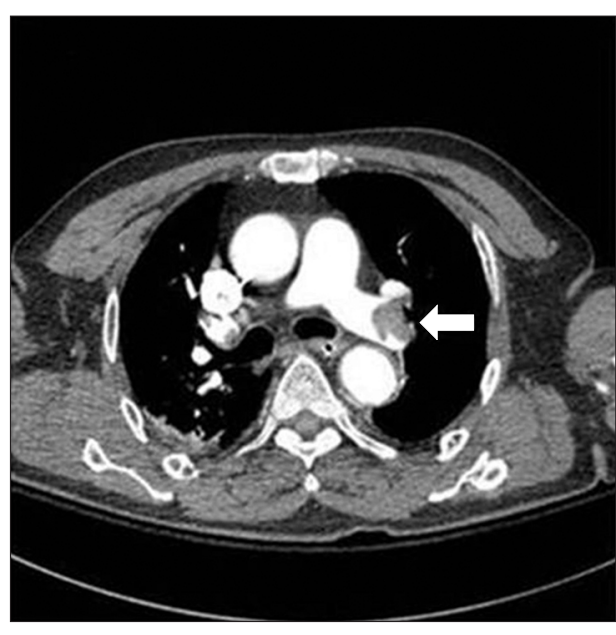

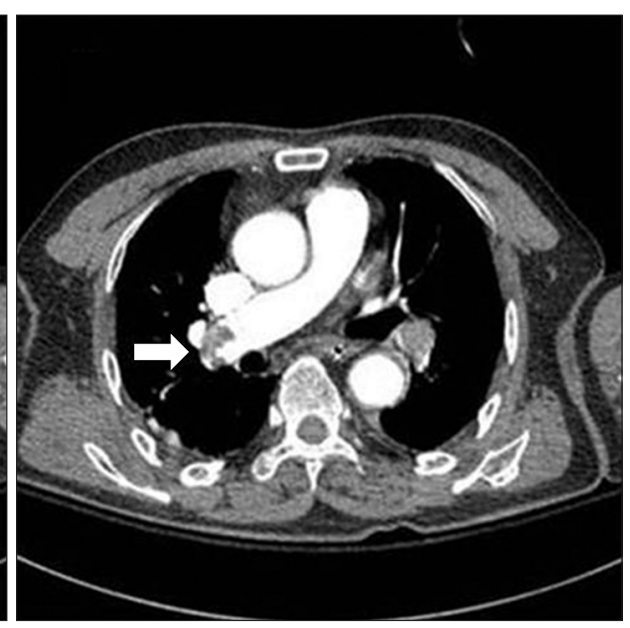

Fig. 1. Chest computed tomography images of thromboembolism (arrows) in the both pulmonary arteries. 


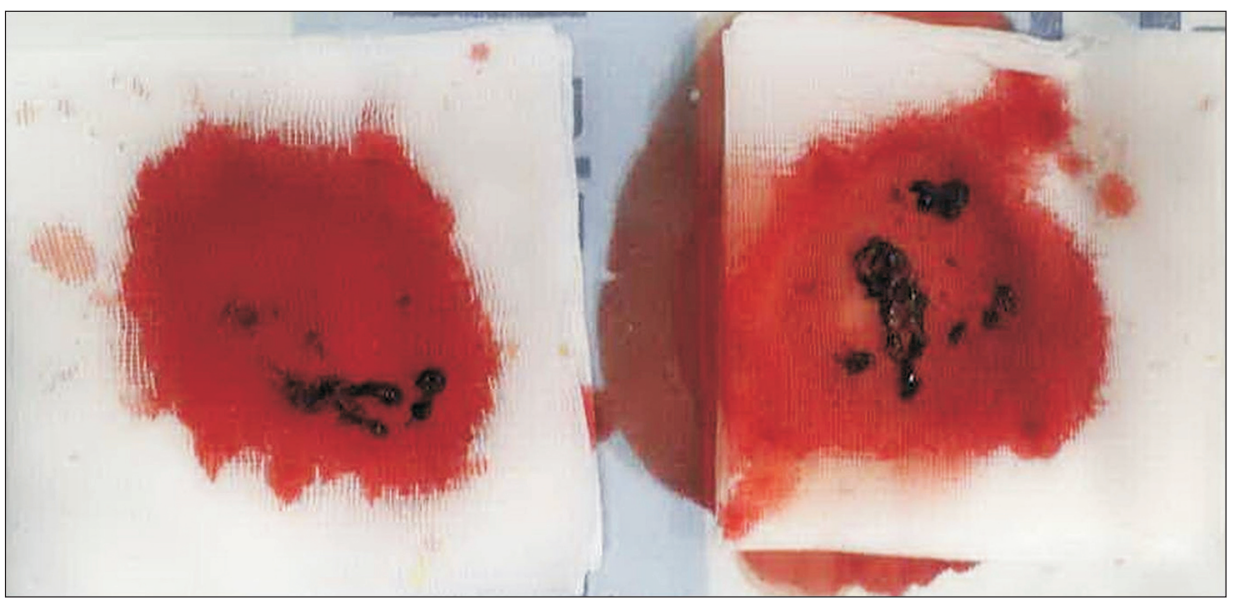

Fig. 2. Thromboembolitic materials removed by percutaneous aspiration thromboembolectomy. damage, and hypercoagulation for thrombus formation [3-6]. Thromboses related to surgery start in the deep veins of the calf, though half of them show spontaneous resolution within 72 hours. About three quarters of progressive thromboses in the proximal vein with the potential to be symptomatic PE occur in the operated-on leg after major orthopedic surgery [2,5]. However, in $80 \%$ of PE patients, there is no evidence of pre-PE peripheral venous thrombosis [6].

After orthopedic surgery, patients usually are on bed rest, which increases the risk of PE. If these patients receive antithrombotic prophylaxis such as anticoagulation, the secondary-intraoperative risk of deep vein thrombosis (DVT) normally is significantly decreased [7]. In many cases, however, appropriate preventive treatment is not administered at all or inadequately so [8]. Early diagnosis and an effective treatment strategy, the latest research $[9,10]$ shows, begins with evaluation of a patient's risk factors for PE. If PE is unlikely, the patient is categorized by PE severity as either high risk or non-high risk rather than by size or location of pulmonary embolus (i.e., massive, sub-massive, non-massive). Risk factors for PE include DVTs, major general surgery, major orthopedic surgery, lower extremity paralysis due to spinal cord injury, fracture of the pelvis, hip, or long bones, trauma, malignancy, myocardial infarction, cardiac or respiratory failure, previous venous thromboembolism, advanced age, and prolonged immobility [11]. It seems that the risks of major orthopedic surgery far outweigh the relevant individual-patient factors [12]. In this regard, DVT risk assessment based on DVT guidelines should be carried out preoperatively for each patient undergoing orthopedic surgery [5,13]. The use of lowmolecular-weight heparin (LMWH) for thromboprophylaxis lowers asymptomatic DVT in cases of total hip replacement or total knee replacement by about half [12]. Antithrombotic prophylaxis may be safely recommended for management of major orthopedic surgery. Although ultrasonography screening is effective for localization of such patients' DVTs, its routine use is avoided, as therapeutic anticoagulation for asymptomatic DVTs can promote bleeding while effecting no marked decrease in the number of PE events [11,13]. The postoperative risk of DVT is the highest in the first two weeks, and the risk of lethal PE between 3 and 7 days [2].

Once hemodynamics becomes unstable, PE management initially focuses on maintaining them and is followed by immediate treatment including anticoagulants or thrombolytic agents. In situations where PE is suspected, it is recommended that administration of anticoagulant be considered before confirming any diagnosis [3]. Hypotension or shock is an indication for thrombolytic agents. These should be started shortly after symptom onset, and are effective for 6 to 14 days [14,15]. Early thrombolysis can be especially effective in cases of right-ventricular failure and a low risk of bleeding [16].

For rapid and effective diagnostic and treatment processes, multidisciplinary collaboration is essential. With respect to a patient's secondary surgery, it is important that the anesthesiologist involved in the initial management becomes the hub of any such interdepartmental communication.

Clinicians need to keep PE in mind and rule it out, especially for high-risk patients scheduled for any orthopedic surgery, even if preventive prophylactic anticoagulation medication has been administered for a sufficiently long period (based on the instructions for LMWH [e.g., dalteparin sodium 5,000 IU subcutaneously once daily] $[17,18])$. According to the opti- 
mal strategies for PE prophylaxis, thromboprophylaxis did not apply to our case, because our patient, lacking any history of venous thoromboembolism, had lower-extremity injuries requiring immobilization [12]. Timely management by multidisciplinary collaboration in doubtful cases of PE can alter initially negative diagnoses to positive and change, thereby, patients' prognoses. In our particular case, notably, PE arose during secondary orthopedic surgery despite preventive anticoagulation therapy, in stark contrast to the first surgery wherein nothing happened. By early diagnosis and treatment carried out through the united effort of interdepartmental colleagues, we were able to overcome a cardiopulmonary collapse and effect successful results without any sequelae.

\section{CONFLICT OF INTEREST}

No potential conflict of interest relevant to this article was reported.

\section{REFERENCES}

1. Kim HJ, Walcott-Sapp S, Leggett K, Bass A, Adler RS, Pavlov H, et al. Detection of pulmonary embolism in the postoperative orthopedic patient using spiral CT scans. HSS J 2010;6:95-8.

2. Kearon C. Natural history of venous thromboembolism. Circulation 2003;107(23 Suppl 1):I22-30.

3. Merli GJ. Pathophysiology of venous thrombosis, thrombophilia, and the diagnosis of deep vein thrombosis-pulmonary embolism in the elderly. Clin Geriatr Med 2006;22:75-92.

4. Kumar DR, Hanlin E, Glurich I, Mazza JJ, Yale SH. Virchow's contribution to the understanding of thrombosis and cellular biology. Clin Med Res 2010;8:168-72.

5. Leme LE, Sguizzatto GT. Prophylaxis of venous thromboembolism in orthopaedic surgery. Rev Bras Ortop 2015;47:685-93.

6. Stein PD, Henry JW. Prevalence of acute pulmonary embolism among patients in a general hospital and at autopsy. Chest 1995;108:978-81.

7. Geerts WH, Berqqvist D, Pineo GF, Heit JA, Samama CM, Lassen MR, et al. Prevention of venous thromboembolism:
American College of Chest Physicians Evidence-Based Clinical Practice Guidelines (8th Edition). Chest 2008;133(6 Suppl):381S453S.

8. Kakkar AK, Cohen AT, Tapson VF, Bergmann JF, Goldhaber SZ, Deslandes B, et al. Venous thromboembolism risk and prophylaxis in the acute care hospital setting (ENDORSE survey): findings in surgical patients. Ann Surg 2010;251:330-8.

9. Schellhaass A, Walther A, Konstantinides S, Böttiger BW. The diagnosis and treatment of acute pulmonary embolism. Dtsch Arztebl Int 2010;107:589-95.

10. Konstantinides SV, Torbicki A, Agnelli G, Danchin N, Fitzmaurice $\mathrm{D}$, Galiè N, et al. 2014 ESC guidelines on the diagnosis and management of acute pulmonary embolism. Eur Heart J 2014; 35:3033-69, 3069a-3069k.

11. Anderson FA Jr, Spencer FA. Risk factors for venous thromboembolism. Circulation 2003;107(23 Suppl 1):I9-16.

12. Falck-Ytter Y, Francis CW, Johanson NA, Curley C, Dahl OE, Schulman S, et al. Prevention of VTE in orthopedic surgery patients: antithrombotic therapy and prevention of thrombosis, 9th ed: American College of Chest Physicians Evidence-Based Clinical Practice Guidelines. Chest 2012;141(2 Suppl):e278S325S.

13. Sociedade Brasileira de Angiologia e Cirurgia Vascular. [Normas de orientação clínica para a prevenção, o diagnóstico e o tratamento da trombose venosa profunda]. J Vasc Br 2005; 4(Suppl 3):S205-20. In Brazil.

14. Yamamoto T. Management of patients with high-risk pulmonary embolism: a narrative review. J Intensive Care 2018;6:16.

15. Daniels LB, Parker JA, Patel SR, Grodstein F, Goldhaber SZ. Relation of duration of symptoms with response to thrombolytic therapy in pulmonary embolism. Am J Cardiol 1997;80:184-8.

16. Chatterjee S, Chakraborty A, Weinberg I, Kadakia M, Wilensky RL, Sardar P, et al. Thrombolysis for pulmonary embolism and risk of all-cause mortality, major bleeding, and intracranial hemorrhage: a meta-analysis. JAMA 2014;311:2414-21.

17. Holmoström M, Berglund MC, Granquist S, Bratt G, Törnebohm E, Lockner D. Fragmin once or twice daily subcutaneously in the treatment of deep venous thrombosis of the leg. Thromb Res 1992;67:49-55.

18. Bhutia S, Wong PF. Once versus twice daily low molecular weight heparin for the initial treatment of venous thromboembolism. Cochrane Database Syst Rev 2013;(7):CD003074. 